\title{
POTRET BUDAYA LOKAL MASYARAKAT TANJUNG RAYA, KABUPATEN AGAM - SUMATERA BARAT DI ERA DIGITAL
}

\author{
Portrait of Local Community Culture, Tanjung Raya, Agam District - West \\ Sumatera in The Digital Era
}

\author{
Dwi Rini Sovia Firdaus ${ }^{1}$, Djuara Lubis ${ }^{2}$, Endriatmo Soetarto ${ }^{2}$, Djoko Susanto ${ }^{2}$ \\ ${ }^{1}$ Dosen Ilmu Komunikasi, FISIB - Universitas Pakuan, \\ ${ }^{2}$ Dosen Departemen Sains Komunikasi dan Pengembangan Masyarakat, \\ Fakultas Ekologi Manusia, Institut Pertanian Bogor \\ E-mail: rinifirdaus1@gmail.com
}

\begin{abstract}
The people of West Sumatra, who have been adhering to the Minangkabau matrilineal cultural tradition, are currently experiencing cultural decay. Many studies speculate that the unique Minangkabau culture will not be too much disturbed by the influx of globalization because in essence the only part that will be eroded is the peripheral part, while the core will remain preserved for all time. This study photographed the people of Tanjung Raya District based on existing family typologies, then saw a shift in norms passed on to teenagers using the six Hofstede cultural dimensions. This study surveyed five types of families with calculations using a simple addition operation. The results of the questionnaire were made high and low criteria, then presented in cobweb graphical form. The assessment indicators are based on the six dimensions of Hofstede's culture. Shifting the teachings of exemplary teachings from Minangkabau culture is determined using the ANOVA test. The results of this study are to map the portrait of Minangkabau culture according to Hofstede and a portrait of each of Hofstede's dimensions in each type of family in Tanjung Raya District. From there, it can be seen how far away the approach of the values taught by the family towards Minangkabau culture is approaching.
\end{abstract}

Keywords: Minangkabau culture, Hofstede, family communication, cultural heritage communication

\begin{abstract}
ABSTRAK
Masyarakat Sumatera Barat yang selama ini memegang teguh tradisi budaya matrilineal Minangkabau, akhir-akhir ini sedang mengalami peluruhan budaya. Banyak penelitian berspekulasi bahwa budaya Minangkabau yang unik tidak akan terlalu banyak terganggu dengan masuknya pengaruh globalisasi karena pada hakikatnya bagian yang akan tergerus hanyalah bagian perifernya saja, sementara bagian inti akan tetap terpelihara sepanjang masa. Penelitian ini memotret masyarakat Kecamatan Tanjung Raya berdasarkan tipologi keluarga yang ada, kemudian melihat pergeseran norma yang diwariskan kepada anak remaja menggunakan keenam dimensi budaya Hofstede. Penelitian ini mensurvei lima tipe keluarga dengan penghitungan menggunakan operasi penjumlahan sederhana. Hasil kuesioner dibuatkan kriteria tinggi dan rendahnya, kemudian disajikan dalam bentuk grafik cobweb. Indikator penilaiannya adalah berdasarkan keenam dimensi budaya Hofstede. Pergeseran ajaran keteladanan dari ajaran budaya Minangkabau ditentukan dengan menggunakan uji anova. Hasil penelitian ini adalah untuk memetakan potret budaya Minangkabau menurut Hofstede dan potret masing-masing dimensi Hofstede pada setiap tipe keluarga yang ada di Kecamatan Tanjung Raya. Dari situ terlihat seberapa menjauh atau mendekatnya nilai keteladanan yang diajarkan oleh keluarga terhadap budaya Minangkabau.
\end{abstract}

Kata kunci: budaya Minangkabau, Hofstede, komunikasi keluarga, komunikasi pewarisan budaya 


\section{PENDAHULUAN}

Sejauh upaya yang telah dilakukan selama ini, langkah preventif untuk mencari asal mula peluruhan dari lingkungan keluarga masih belum pernah ditelusuri. Penelitian ini ingin membuktikan bahwa peluruhan justru berpotensi datang dari inner-circle kehidupan kita, yaitu keluarga. Paparan penelitian ini, selain dilihat dari sudut pandang orang tua, juga diestimasi dari sudut pandang anak remaja berusia 10 - 19 tahun. Hofstede (2010) pernah berpendapat, pada usia sekitar 10 tahun, anak secara berimbang mendapatkan nilai (values) dari keluarga sekaligus praktik-praktik (practices) dari sekolahnya. Seiring dengan bertambahnya usia anak, pengaruh values dari keluarga semakin berkurang sementara pengaruh practices semakin bertambah. Oleh karena itu, penelitian ini memberi batasan usia pada saat dimana anak sudah memiliki pertimbangan relatif stabil namun belum cukup untuk dikategorikan sebagai dewasa. Usia tersebut merupakan usia remaja dan oleh Kementerian Kesehatan ${ }^{1}$ diklasifikasikan antara usia 10-19 tahun.

Belum ada angka yang jelas untuk menggambarkan jumlah anak yang sudah tidak mengenal budaya di tempat mereka tinggal saat ini, dan berapa jumlah keluarga yang masih berada pada jalur mewariskan ritual-ritual Minangkabau. Ketika kondisi ini semakin mengkhawatirkan, penelitian ini menjadi sebuah wake up call bagi masyarakat dan pemerintahan lokal bahwa pengajaran tentang keteladanan di dalam keluarga ada yang memperdekat dan ada juga yang menjauh-kan anak dari ajaran budaya Minangkabau. Dengan demikian, penting kiranya untuk menjabarkan pola pewarisan dari bebera-pa kategorisasi keluarga yang ada di Kecamatan Tanjung Raya saat ini. Mereka bukan lagi mewariskan budaya Minangkabau, melainkan mewariskan budaya lokal hasil dari berbagai macam percampuran budaya asing dengan budaya Minangkabau selama ini. Upaya ini adalah untuk membantu keluarga agar memahami pola komunikasi mana yang dekat dan sejalan dengan ajaran budaya Minangkabau. Jika kita gagal membantu anak-anak sebagai generasi penerus pewarisan, maka tidak boleh ada perkataan bahwa kita tidak tahu apa yang telah mereka lalui selama ini karena seyogyanya kita berkontribusi terhadap peluruhan yang terjadi.

Di Kecamatan Tanjung Raya, perilaku sebagian besar masyarakat sudah tidak mencerminkan ciri budaya Minangkabau yang mengacu pada harmonisasi yang dicontohkan oleh alam dan agama Islam. Keadaan ini memprihatinkan para pemuka adat karena upaya pewarisan budaya selama ini menjadi sia-sia. Akhirakhir ini, peran keluarga luas (keluarga sepesukuan dan sekaum) semakin tidak nyata terlihat ikut andil dalam mendidik anak kemenakan ${ }^{2}$. Dengan sedikitnya peran keluarga luas, dapat mengisyaratkan bahwa masyarakat Minangkabau semakin lemah dalam mewariskan budayanya sendiri. Keluarga inti menjadi penting sebagai sebuah unit ekonomi dan hunian. Hubungan ayah dan anak sekarang menentukan dalam pemilikan harta penca-harian walaupun prinsip matrilineal dalam pewarisan harta pusaka tinggi ${ }^{3}$ masih berlaku. Saat ini, ayah dan ibu secara prinsip merupakan penjaga anak-anak dalam ruang domestik.

\footnotetext{
${ }^{1}$ Menurut data Kementrian Kesehatan RI tahun 2014, kategori usia remaja dibedakan atas dua macam, yaitu: remaja awal (berusia 10-14 tahun) dan remaja akhir (berusia 15-19 tahun).

${ }^{2}$ Anak kemenakan adalah istilah untuk anak yang merupakan tanggungjawab keluarga besar dalam mendidik

${ }^{3}$ Harta pusaka tinggi merupakan harta pusaka berupa tanah yang diwariskan oleh nenek moyang dan tidak

boleh dijual melainkan hanya boleh diolah untuk dimanfaatkan hasilnya secara komunal
} 
Sementara mamak masih tetap berwenang dalam kaitan dengan kelompok kekerabatan kaum atau paruik.

Beberapa permasalahan dari budaya Minangkabau yang menjadikannya terli-hat usang dan kalah dibandingkan dengan kepraktisan yang diusung oleh budaya asing, diantaranya: (1) budaya Minangkabau dirasa sudah kurang praktis serta kebanyakan ritual Minangkabau relatif rumit dan mahal, (2) ajaran dari kearifan lokal kebanyakan menggunakan peribaha-sa yang mengandung kata-kata kiasan sehingga sulit untuk dipahami oleh remaja zaman sekarang, (3) adanya sinyal bahwa tingkat pemahaman remaja terhadap nilai-nilai budayanya masih rendah, (4) sistem kekerabatan di Minangkabau cukup rumit dan sulit untuk dipahami sehingga belum mendarah daging di kalangan remaja di Sumatera Barat saat ini, (5) hubungan keluarga inti sudah mulai dianggap lebih bermanfaat, sehingga remaja tidak terbiasa menganggap bahwa peran seorang mamak tungganai (saudara laki-laki dari ibu) adalah lebih penting dibandingkan dengan peran ayahnya sendiri di dalam keluarga (Syafrial 2015).

Meskipun Kecamatan Tanjung Raya tengah mengalami peluruhan budaya, terdapat beberapa unsur yang masih dipertahankan sebagai ciri utama sistem keke-rabatan matrilineal Minangkabau, yaitu: (1) pola menetap uxorilokal ${ }^{4}$, (2) harta pusaka tinggi yang masih menjadi milik bersama, (3) sistem perkawinan ekso-gami ${ }^{5}$ dan (4) tradisi merantau (Syafrial 2015). Perihal merantau, lebih lanjut Kato (2005) menjelaskan bahwa "kecenderungan laki-laki Minangkabau pergi merantau untuk mencari kekayaan, ilmu pengetahuan, dan kemashuran. Hal ini mulai diperhatikan sejak permulaan abad ke-20". Kegiatan merantau, dari waktu ke waktu memiliki tujuan yang berbeda-beda. Kato (2005) membaginya dalam tiga macam kategori, yaitu: (1) merantau untuk pemekaran nagari, terjadi sejak masa legenda hingga awal abad ke-19, (2) merantau keliling, terjadi sejak akhir abad ke-19 sampai 1930an, dan (3) merantau Cino, terjadi sejak 1950an hingga seka-rang. Dijelaskan juga oleh Kato bahwa orang sekarang yang merantau belum tentu berniat untuk kembali lagi ke kampungnya. Bahkan sekarang laki-laki pergi merantau untuk bekerja justru membawa anak dan istrinya. Orang-orang yang mencari ilmu dan berkuliah telah terpikat oleh pesona daerah rantaunya. Kampung halaman hanya dikunjungi di saat tertentu saja, karena tidak menjanjikan apa-apa, setidaknya secara ekonomi dan pendidikan. Inilah definisi dari merantau cino, dan inilah kondisi yang sedang dihadapi oleh Kecamatan Tanjung Raya. Bahkan dari data BPS Kabupaten Agam tahun $2010^{6}$ menjelaskan bahwa, jumlah penduduk yang pergi lebih banyak daripada jumlah yang datang. Hal ini menjadi kekhawatiran tersendiri ketika ekspektasi untuk mewariskan budaya lokal tertumpu di atas pundak masyarakat yang menetap (tidak merantau). Meskipun semangat pulang basamo terus digalakkan oleh perantau Minang, namun hal ini hanya terjadi sesekali waktu saja, misalnya pada perayaan 1 Muharram, lebaran, dan sebagainya. Sisanya, tanggungjawab membangun nagari sekaligus melestarikan budaya lokal kembali diemban oleh sejumlah kecil masyarakat menetap yang kian hari kian berkurang. Mengutip dari Graves (2007), "tanpa disadari merantau dapat menciptakan kemunduran, dimana nagari-nagari yang tadinya menyimpan sejarah

\footnotetext{
${ }^{4}$ Uxorilokal adalah adat menetap sesudah nikah yang menentukan bahwa pasangan pengantin baru menetap di sekitar pusat kediaman kaum kerabat istri.

${ }^{5}$ Perkawinan eksogami adalah suatu perkawinan antar etnis, klan, suku, kekerabatan dalam lingkungan yang sama.

${ }^{6}$ Badan Pusat Statistika http://sp2010.bps.go.id/ diakses tgl 30 September 2016.
} 
maupun potensi sumber daya ditinggalkan begitu saja, kemudian lama kelamaan menjadi mati sebagai korban dari kesuk-sesannya sendiri. Sebuah perangkap ironis dari semangat pencarian nenek moyang mewarisi tradisi merantau". Masyarakat Minangkabau telah terlalu lama tenggelam dalam euphoria merantau. Awe (2010) menjelaskan bahwa "mempertahankan tradisi berarti menciptakan stabilitas, jika tidak dipertahankan kondisi ini dapat menyebabkan pergeseran dalam praktik kemasyarakatan atau bahkan menimbulkan kerusakan dalam lingkungan budaya yang ada selama ini”. Dengan adanya tradisi merantau yang sudah menjadi stereotip masyarakat Minangkabau, jumlah penduduk yang menetap semakin berkurang sehingga dapat membahayakan stabilitas dan berpo-tensi menimbulkan kerusakan lingkungan budaya di Tanjung Raya. Definisi 'merantau' pada penelitian ini disesuaikan dengan kondisi di lapangan yaitu ayah sebagai perantau risen. ${ }^{7}$ Kebanyakan penelitian tentang tradisi merantau lebih mengangkat fenomena tentang perantau yang menetap/bukan risen sebagai sumber kerusakan lingkungan budaya (Graves 2007, Kato 2005).

Selain merantau, tradisi yang masih dipertahankan adalah sistem perkawinan eksogami. Perkawinan eksogami yang semula bertujuan untuk mencegah terjadinya perkawinan sesama saudara, sekarang justru berdampak pada pola asuh terhadap anak, karena orang tua yang berbeda budaya berbeda pula cara mengajarkan norma-norma dalam keluarganya. Pendidikan anak yang berasal dari orang tua yang multietnik dengan pengaruh yang seimbang, berpotensi menimbulkan konflik dan kebingungan pada anak sehingga mereka cenderung "melarikan diri" dan berlindung di balik pengaruh pergaulannya sendiri di luar rumah, misalnya di sekolah, di kegiatan keagamaan, dan di lingkungan tetangga, atau (buruknya) melarikan diri ke narkoba.

Istilah cultural decay (DeSilvey 2017, John \& Ashgate 2001) dan cultural erosion (Wahab et.al. 2012, Awe 2010, Assmann 2010) atau disebut juga dengan peluruhan budaya digunakan untuk menggambarkan tentang berkurangnya bahkan hilangnya aspek-aspek tertentu pada suatu budaya akibat pengaruh dari budaya lainnya yang lebih kuat. Sebaliknya, penelitian ini justru menyoroti peluruhan yang disebabkan oleh pengaruh dari dalam, di dalam "lingkungan tempat proses proksimal terjadi”, meminjam istilah dari Bronfenbrenner (1979). Merekalah yang disebut oleh Bronfenbrenner sebagai orang-orang yang berada dalam sistem konsentris terdalam seorang individu, yaitu keluarga. Jika dilihat lagi ke belakang, terlalu luas untuk menyalahkan negara sebagai penyebab peluruhan yang terjadi di Sumatera Barat, khususnya di Kecamatan Tanjung Raya, Kabupaten Agam. Mubah (2011a) mengatakan, sebagai negara berkembang Indonesia lemah dalam penguasaan teknologi komunikasi dan informasi, kemudian pasar Indonesia sangat luas sehingga dijadikan target potensial bagi penyebaran identitas budaya negara-negara maju. Menurut Koentjaraningrat (1990), kebudayaan mentalitas dan pembangunan masyarakat Indonesia masih di bawah taraf normal. Diperlukan mentalitas yang menilai tinggi hasil karyanya sendiri. Bukan hanya berorientasi pada harta untuk dikonsumsi dengan hasilnya berupa kedudukan sosial yang menambah gengsi.Sementara itu, Scholte (2001) berpendapat bahwa Indonesia sudah gagal mengamankan garis teritorial untuk mempertahankan kekuatan domestik melawan ancaman dari luar. Padahal sesederhana masuknya media elektronik ataupun masuknya alat komunikasi

${ }^{7}$ Perantau risen adalah perantau sementara yang bekerja di rantau, yang sewaktu-waktu pulang ke kampung untuk menyerah-kan uangnya kepada istri dan anak-anaknya. 
massa seperti televisi, radio, internet, film, majalah, surat kabar ke wilayah di sekeliling Danau Maninjau ini saja sudah cukup mampu menciptakan pola homogenisasi yang dimaksudkan oleh Tomlinson (2003) dan Mubah (2011b). Jadi kalau dilihat kembali, banyak faktor yang mengakibatkan peluruhan budaya, namun penelitian ini lebih berfokus pada keluarga, karena keluarga merupakan unit dasar dari suatu komposisi masyarakat, dan merupakan sarana paling efektif dalam membuat peraturan dan keseimbangan sosial (Turner \& West 2006). Sebagai komunitas pertama di mana setiap orang berhubungan, dan otoritas pertama di mana seseorang belajar untuk hidup, keluarga membentuk nilai paling dasar suatu masyarakat (Turner \& West 2006).

Di saat masyarakat tengah diributkan oleh fenomena peluruhan budaya Minangkabau, belum ada yang tahu sejauh mana pergeseran itu terjadi dan keluarga tipe apa yang menjadi pionir dalam melestarikan budaya Minangkabau. Untuk itu, diperlukan refleksi dan aksi untuk memposisikan peran komunikasi keluarga dalam pewarisan budaya lokal. Oleh karena itu, penelitian ini merumuskan permasalahan, tentang bagaimana potret budaya Minangkabau menurut Hofstede dan bagaimana potret masing-masing dimensi Hofstede pada setiap tipe keluarga yang ada di Kecamatan Tanjung Raya.Tujuan penelitian ini adalah untuk memetakan potret budaya Minangkabau menurut Hofstede dan potret masing-masing dimensi Hofstede pada setiap tipe keluarga yang ada di Kecamatan Tanjung Raya.

\section{METODE PENELITIAN}

Penelitian ini mensurvei keluarga inti (ayah, ibu dan anak) sebagai satu unit responden, dan memotretnya dari keenam dimensi Hofstede. Survei dilakukan mela-lui penyebaran kuesioner di lapangan. Hasil survei kemudian diolah dengan ope-rasi penjumlahan sederhana. Pada kuesioner yang menggunakan skala Likert 1-4 dilakukan analisis rataan (per soal oleh setiap responden) untuk membuat kriteria "tinggi dan rendah". Penentuan jumlah sampel menggunakan presisi 10\% dan tingkat kepercayaan 95\% menggunakan rumus Taro Yamane karena jumlah popu-lasi melebihi 500 unit keluarga (Ardial 2014).

Data akhir ditampilkan dalam bentuk grafik cobweb tentang potret masingmasing dimensi Hofstede pada kelima tipe keluarga yang ada, yaitu: ayah Minang \& ibu Minang dengan ayah me-rantau (AM+IM ayah merantau), ayah Minang \& ibu Minang dengan ayah mene-tap (AM+IM ayah menetap), ayah Minang \& ibu non-Minang (AM+InM), ayah non-Minang \& ibu Minang (AnM+IM), ayah nonMinang \& ibu non-Minang (AnM+InM). Penelitian ini menggunakan keenam dimensi budaya Hostede (Hofstede 2010, Huo \& Randall 1991, Jones 2007, McSweeney 2002), yaitu: (1) Power Distance Index (PDI), (2) IndividualismvsCollectivism(IDV), (3) Uncertainty Avoidance Index (UAI), (4) MasculinityvsFemininity(MAS), (5) Long-Term Orientation (LTO), (6) Indulgence versus Restraint (IVR).

Jumlah kepala keluarga di Nagari Sungai Batang adalah sekitar 2000 kepala keluarga dan di Nagari Maninjau sekitar 1700 kepala keluarga. Oleh karena responden merupakan satuan unit keluarga yang terdiri dari ayah dan ibu yang memiliki anak remaja, maka populasi untuk penelitian ini adalah sebanyak 3700 kepala keluarga. Anak merupakan remaja de-ngan usia 10-19 tahun. Jumlah sampel adalah 97,37, kemudian mengalami pembulatan dan penambahan menjadi 106 kepala keluarga untuk mendapatkan hasil yang lebih baik. Adapun uji 
validitas (menggunakan Pearson's product moment) dan reliabilitas kuesioner (menggunakan alpha cronbach), dilakukan pada 30 unit keluarga selain responden. Perge-seran ajaran keteladanan dari ajaran budaya Minangkabau pada lima tipe keluarga (AM+IM ayah merantau, AM+IM ayah menetap, AM+InM, AnM+IM, AnM+IM) ditentukan dengan menggunakan uji anova.

\section{HASIL DAN PEMBAHASAN}

Potret budaya Minangkabau dalam penelitian ini diambil dari salah satu elemen ajaran alam takambang jadi guru yaitu tentang delapan falsafah alam (Navis 1984), yaitu: (1) harga diri, (2) malu yang tidak dapat dibagi, (3) pola awak samo awak, (4) rasa dan periksa, (5) kesamaan dan kebersamaan, (6) seiya sekata, (7) pola penyesuaian yang serasi, dan (8) hidup bertahan dan mempertahankan hidup. Kedelapan falsafah alam ini kemudian dianalisis dengan menggunakan keenam konsep dimensi budaya Hofstede, yaitu: (1) power distance, (2) individualism vs collectivism, (3) uncertainty avoidance, (4) masculinity vs femininity, (5) long term orientation, (6) indulgence vs restraints.

\section{1) Harga Diri}

Konsep harga diri yang diajarkan pada budaya Minangkabau agak lebih maskulin. Mempertahankan harga diri berarti meletakkan kedudukan diri sendiri agar menjadi lebih berarti atau setidaknya sama dengan orang lain. Konsep harga diri bagi orang Minangkabau dimaknai sebagai malawan dunia urang (melawan dunia orang lain). Konsep ini mengandung amanat untuk hidup bersaing terus mene-rus dalam mencapai kemuliaan, kepintar-an, dan kekayaan seperti yang dimiliki orang lain sehingga melahirkan ide untuk kemajuan. Nilai yang dicapai pada persa-ingan dalam melawan dunia orang lain diukur dengan kondisi dan prestasi orang lain. Artinya bila orang mampu, kita pun mampu. Dan sebaliknya bila kita mampu, orang lain tentulah mampu juga. Oleh karena setiap orang dengan egonya masing-masing membuahkan ambisi, persaingan antara sesama dapat menjadi pertarungan untuk saling mengalahkan. Untuk menghindari bentrokan ini, masyarakat membuat hukum dan aturan yang mengikat setiap individu agar tidak terlepas dari kendali, yaitu dengan sistem kekerabatan dan ekonomi komunal berdasarkan paham etnis yang menganut stelsel matrilineal serta sistem perkawinan antar etnis dengan cara eksogami ${ }^{8}$. Di sinilah awalnya nilai individualisme menjadi rendah. Budaya Minangkabau mengajarkan agar masyarakatnya berjuang dan ber-prestasi untuk kebanggaan kelompoknya dan dinikmati bersama di dalam kelompok persaudaraannya.

\section{2) Malu yang tidak dapat dibagi}

"Meletakkan harga diri lebih rendah dari orang lain terutama orang di luar lingkungan kekerabatan sendiri, merupakan aib yang paling tidak bisa dimaafkan" (Navis 1984b). Aib ini bahkan tidak dapat ditebus, dibayar, dan dibagi-bagi. Adat yang tinggi adalah memiliki rasa malu, tidak mengeluh, apalagi menangisi kesulitan hidup, karena rasa malu ditanggung oleh seluruh keluarga bahkan oleh seluruh masyarakat di kampung halaman. Seolah masyarakat telah mengabaikan adat mereka yang tinggi, yaitu saling menjaga harga diri sesama kerabatnya. Untuk menjaga agar tidak seorang pun akan terkena imbas dari aib ini, ajaran adat menyuruh setiap orang pandai menyimpan aib kerabatnya dari mata orang lain. Aib yang memalukan harus merupakan rahasia yang perlu disembunyikan.

\footnotetext{
${ }^{8}$ Eksogami adalah perkawinan dengan orang dari adat yang berbeda
} 
"Mamakan habih-habih, manyuruak hilang-hilang" (jika makan harus sampai tuntas, jika bersembunyi harus sampai betul-betul hilang), artinya jika seseorang membuat malu (aib) ia sendirilah yang pertama-tama harus ber-tanggungjawab, dan malu ini sifatnya tidak dapat dibagi ke orang lain.

Jika harus dibuka untuk mencari perbaikan, aib hanya akan disampaikan kepada kerabat yang paling dekat. Jika kerabat yang paling dekat tidak dapat menyelesaikannya sendiri, maka akan dibawa kepada kerabat yang lebih luas. Tidak boleh kepada orang lain di luar lingkungan kekerabatan. Untuk menutupi rasa malu dalam menjaga harga diri, kepada mereka diajarkan agar mampu memikul resiko dan konsekuensinya. Andaikata tidak ada harta untuk mengatasi kesulitan, akali kesulitan itu dengan apa saja, meskipun dengan menipu'. Tidak mau mendapat malu karena tidak mampu melawan dunia orang lain merupakan motivasi untuk mencapai kemajuan dan kebanggaan serta menjaga harga diri. Hasilnya dapat berbentuk positif, tapi juga berbentuk negatif.

\section{3) Pola awak samo awak}

Alam Takambang Jadi Guru mengajarkan orang Minangkabau untuk membentuk masyarakat yang komunalistik (hidup berkelompok), baik dalam hal tempat kediaman, sosial, maupun dalam usaha. Di dalam dimensi Hofstede termasuk ke dalam nilai individualism yang rendah. Setiap kelompok bergabung dengan kelompok lain yang lebih besar. Dan setiap kelompok kecil saling berbaur dengan identitas masing-masing yang terpelihara dalam suatu ikatan kebudayaan dan falsafah yang sama. Dalam kelompok sosial, kaum bergabung dalam satu suku, dan suku bergabung dalam satu istilah yang dinamakan urang awak. Selain awak adalah orang lain yang tidak akan dapat dimasukkan ke dalam lingkaran. Bahkan dalam hubungan perkawinan pun, pasangan suami istri tetap seperti air dan minyak karena sistem perkawinan yang eksogami. Dengan demikian berarti suami atau istri tidak pada tempatnya menceritakan kedukaannya pada pasangannya. Kedukaan hanya boleh disampaikan kepada kerabat masing-masing menurut tali darah bagi yang berbudaya matrilineal. Hubungan awak samo awak yang demikian erat senantiasa dapat menghilangkan fungsi hukum formal yang ada dalam masyarakat Minang, jika ada pelanggaran atau persengketaan di antara mereka. Pola awak samo awak membuat masyarakat tidak melihat adanya sekat di antara mereka, merasa tidak perlu diatur dengan norma yang ketat jika sedang bersama dan cenderung menjadi lebih konsumtif, serta lebih menghargai kewajiban sosial untuk membalas bantuan orang lain. Di dalam dimensi Hofstede pola ini memiliki nilai indulgence yang besar serta berorientasi jangka pendek.

\section{4) Rasa dan periksa}

Di Nagari Maninjau, anak harus memiliki tenggang rasa dan mampu beradaptasi dengan lingkungannya. Sudah sangat jelas bahwa budaya Minangkabau menganjurkan adanya persaingan agar berada pada suatu tingkat yang dapat mengangkat harga diri pribadi dan kaum kerabatnya. Tapi persaingan ini harus cukup adil agar dapat menciptakan harmoni di tengah masyarakat. Persaingan kelompok masyarakat yang terdiri dari berbagai suku dapat menimbulkan perkelahian massal bahkan peperangan. Namun konflik-konflik

\footnotetext{
${ }^{9}$ Ungkapan yang sangat luas dikenal masyarakat Indonesia adalah tentang orang Minang yang suka menipu, ialah "Padang bengkok". Tampaknya, tabiat menipu mereka ini selain karena tabiat manusia biasa, juga merupakan keharusan karena mereka tidak suka dan berpantang meminta belas kasihan dari orang lain yang bukan kerabatnya. Selanjutnya, orang yang gampang tertipu akan menghilangkan rasa simpati kepadanya karena dipandang sebagai orang bodoh, orang yang memalukan kaum kerabatnya sendiri.
} 
fisik dapat dihindari karena adanya aturan perkawinan yang mengharuskan terjadinya perkawinan antar suku pada budaya Minangkabau. Di Nagari Maninjau sendiri, perkawinan antar suku juga dianjurkan.

Rasa dan periksa berarti segala sesuatu ditimbang dengan ukuran perasaan yang sama dan dengan pemeriksaan yang senilai. Ukuran 'rasa' merujuk pada bathin dan hati nurani. Jadi setiap kesenangan yang kita lakukan hendaknya disukai pula oleh orang lain, setidaknya jangan sampai mengganggu orang lain. Sedangkan 'periksa' merujuk pada akal pikiran dan nalar, diukur menurut alur yang lazim. Orang Minangkabau memiliki pepatah raso mandaki, pareso manurun;

"setiap tindakan yang berasal dari rasa harus mendaki ke nalar (dipe-riksa dengan nalar), sementara yang sudah benar menurut nalar harus diturunkan (diperiksa dengan hati nurani). Itulah mengapa ma-syarakat Minangkabau selalu menyebut akal dengan perkataan 'aka-budi' (akal budi). Akal dan budi dipandang sebagai suatu hal yang komplementar, dan ini memperli-hatkan prinsip perimbangan-pertentangan"(wawancara dengan Mamak Pusako).

"Mamangan (sejenis pepatah) tentang pentingnya rasa dan periksa, misalnya: "baa dek urang bagitu pulo dek awak" (bagaimana terasa oleh orang lain, begitu pula yang terasa oleh kita), "dipiciak jangek, sakik dek awak sakik dek urang " (jika dicubit kulit, orang me-rasa sakit, begitu juga kita)" (wa-wancara dengan Khatib Basa).

"Akan tetapi, seandainya dalam keadaan yang memaksa, saat nilai rasa dan periksa tidak mungkin dilaksanakan lagi, maka orang pun dapat memakai cara lain yang tidak menurut alur yang biasa, asalkan tidak merugikan orang lain” (mantan wali Nagari Maninjau).

\section{5) Kesamaan dan kebersamaan}

Nilai kesamaan dan kebersamaan di Nagari Maninjau diartikan sebagai kemampuan seseorang untuk bersosialisasi, tidak berkompetisi, suka bergotong royong dan menghargai orang lain. Fungsi "kesatuan" bagi orang Minang lebih meli-hatnya sebagai kelompok yang besar melindungi kelompok yang kecil. Persatuan mereka lebih seperti sekumpulan lidi yang diikat menjadi sapu lidi. Bukan persatuan antara kerikil, pasir dan semen sehingga membentuk beton. Oleh karena itu, orang Minang tidak memakai istilah persatuan dalam tata kehidupan. Mereka menggunakan istilah sama dan bersama. Jika sama dan bersama dihimpunkan semua, bukanlah menjadi satu, melainkan menjadi kompak. Misalnya dalam mencari nafkah, mereka senantiasa mengerjakannya bersama dengan keluarga, karena harta yang didapat pada hakikatnya untuk keperluan kerabat mereka yang sedarah, bukan untuk diri sendiri. Selain dari tata ekonomi mereka yang komunalistis, sistem penggarapannya pun dilakukan secara bersamasama. Demikian juga dengan harta benda lainnya, seperti sawah dan ladang serta rumah adalah milik bersama.

Sebagaimana lazimnya penduduk agraris, orang Minang hidup saling membantu, bekerjasama dengan pola berat sama dipikul, ringan sama dijinjing. Artinya, segala tugas dan beban untuk kepentingan bersama dikerjakan bersama pula. Akan tetapi karena keadaan orang tidak sama, ada yang kaya dan ada yang tidak kaya, ada yang kuat dan ada yang tidak kuat, maka diterapkan sistem kerjasama berdasarkan keseimbangan. Ini berarti yang kaya dan yang kuat 
memiliki kewajiban lebih banyak dari yang lemah. Sistem ini disebut sebagai gadang kayu, gadang bahannyo (besar batang kayunya berarti besar pula jumlah bahannya). Sementara itu, konsep kebersamaan dalam budaya asing diartikan sebagai 'kerjasama' yaitu:

"An autonomous association of persons united voluntarily to meet their common economic, social \& cultural needs \& aspirations through a jointlyowned \& demo-cratically-controlled enterprise" (Prakash 2003).

Suatu kerjasama harus bebas menentukan dengan siapa seseorang ingin melakukannya, tidak ada kewajiban karena kegiatan kerjasama hendaknya dilakukan secara sukarela. Seseorang bebas untuk terlibat ataupun ingin meninggalkan suatu kerjasama tersebut. Orang-orang yang bekerjasama seharusnya menuju pada kesamaan kepentingan dalam aspek ekonomi, sosial dan budaya. Tentunya di masa yang akan datang, suatu kerjasama ditujukan untuk kehidupan yang lebih baik secara budaya, intelektual dan spiritual, merupakan cara terbaik seseorang berkontribusi kepada masyara-katnya (Prakash 2003).Di dalam dimensi Hofstede, kesamaan dan kebersamaan memiliki nilai individualisme dan power distance yang rendah, sementara tetap maskulin, indulgence, berorientasi jangka pendek, serta selalu menghindari ketidak-pastian.

\section{6) Seiya sekata}

Makna dari seiya sekata di Nagari Maninjau berarti seseorang harus mampu menjunjung nilai kebersamaan, bisa menjaga perasaan orang lain dan menjaga pertemanan dengan baik. Dari rasa persamaan dalam kehidupan bersama yang menyeluruh, orang Minang dituntut oleh suatu aturan yang dinamakan saiyo sakato (seiya sekata). Makna yang dikandung dalam istilah saiyo adalah baiyo-iyo (beriya-iya) dan batido-tido (bertidak-tidak). Artinya, seseorang harus bersungguh-sungguh jika meyakini suatu masalah, bukan asal mengiyakan atau menyatakan persetujuan untuk segala apa yang diputuskan oleh orang lain jika hati kecilnya tidak setuju. Orang diajarkan jika berdiskusi tentang suatu masalah, harus berakhir dengan kata mufakat karena mufakat memiliki rukun yaitu kebulatan pendapat. Kebulatan kata itulah yang dimaksud dengan sakato.

Dalam pengertian sosiologis, seiya sekata mempunyai makna homogenitas masyarakat yang berlandaskan kehidupan komunal. Dalam pengertian ketatanegaraan, ini mengandung makna demokrasi. Oleh karena itu, rasa persamaan dan kebersamaan lebih tinggi nilainya daripada seiya sekata. Seiya sekata dapat juga timbul karena ada rasa segan untuk menyatakan suatu pendapat yang berbeda dari pendapat umum. Sedangkan rasa persamaan dan kebersamaan meletakkan setiap orang pada nilai yang sederajat pada tingkat pertama. Pemahamannya dari sudut pikiran demokrasi, bahwa perbedaan pendapat tidak berarti tidak hendak ikut bersama yang lain. Bahkan dalam permusyawara-tan atau mufakat diperlukan pikiran yang berbeda agar masalah dapat diselesaikan dengan sebaik-baiknya.

\section{7) Pola penyesuaian yang serasi}

Sebagai falsafah yang berguru pada alam, orang Minang memandang falsafah Minangkabau sebagai ajaran yang abadi. Keabadian ini bukan karena sifatnya yang statis dan kaku, melainkan karena kemam-puannya menyesuaikan diri dengan keadaan yang senantiasa berubah, sebagaimana alam yang juga senantiasa berubah, namun harkatnya akan tetap abadi. Ajaran ini mengajarkan 
kemampuan dalam penyesuaian diri dengan mengatakan bahwa penyesuaian merupakan seni hidup manusia jika ingin tetap selamat. Pantun-pantun memberikan pemahaman bahwa orang Minang menafsirkan alam dengan baik. Alam itu terus hidup meski ada yang patah, misalnya pohon maka ia akan tumbuh terus. Zat alam yang hilang seperti air dan api, ia akan terus ada. Sikap yang diajarkan adalah sikap optimis asalkan mampu menyesuaikan diri dengan alam dan lingkungannya. Di mana pun orang hidup, aturan setempat haruslah dipakai, namun bukan berarti tidak memiliki pendirian tetap. Dalam beberapa pameo secara konkrit dijelaskan betapa orang Minangkabau harus mampu menyesuaikan diri tanpa kehilangan identitas dirinya atau kebudayaan bangsanya. Keadaan dapat berubah dan bagi orang yang bijaksana perubahan ini diikutinya tanpa mengubah landasan hidupnya.

\section{8) Hidup bertahan dan mempertahan-kan hidup}

Di dalam falsafah alam, setiap manusia harus mampu menyesuaikan dirinya dengan alam, lingkungan hidup dan dengan sesamanya yang merupakan bagian dari alam. Adapun pola penyesuaian yang serasi adalah menyesuaikan diri dengan keadaan yang lebih baik. Salah satunya dengan menandingi kejayaan orang lain. Ajaran alam takambang jadi guru pada dasarnya mencegah adu kekuatan antara pihak-pihak yang berlomba dalam kejayaan, sebab yang kuat tidak diberi hak untuk melawan pihak yang lemah. Namun, orang Minang juga memahami hukum dialektis yang mereka sebut bakarano bakajadian (bersebab berakibat). Sewaktuwaktu akan timbul persengketaan di antara mereka yang tidak dapat diselesaikan. Ajaran alam takam-bang jadi guru mengajarkan istilah "pertahankan" dan "pagari". Dalam sikap mempertahankan atau memagari diri dan lingkungan, pola "berbilik kecil berbilik besar" sangat dipegang teguh. Lebih diutamakan untuk melindungi sanak saudara dulu, kemudian orang sekampung. Selanjutnya orang yang sepesukuan, lalu orang dalam lingkungan senagari (bisa juga diartikan sebagai setanah air).

Hasil analisis menggunakan dimensi budaya Hofstede dapat digambarkan sebagai berikut: di dalam elemen ajaran falsafah alam terkandung nilai kompetisi yang tinggi (MAS tinggi), menghindari ketidakpastian yang tinggi (UAI tinggi), dan menganjurkan upaya penekanan tingkat kebutuhan serta pengaturan menggunakan norma sosial yang ketat (IVR tinggi). Masyarakat diajarkan untuk hidup berkelompok (IDV rendah), lebih menghargai tradisi, lebih bangga terhadap budaya dan negara, berkeinginan untuk melestarikan keaslian budaya, lebih menghargai kewajiban sosial, serta lebih senang membalas suatu pemberian dan bantuan dari orang lain (LTO rendah). Budaya Minangkabau juga mengajarkan bahwa hierarki secara kodrati merupakan kemunduran (PDI rendah) (Firdaus 2018). Satu persatu potret dari keenam dimensi budaya Hofstede di Kecamatan Tanjung Raya, dipaparkan sebagai berikut: 
Potret Power Distance Masyarakat Tanjung Raya

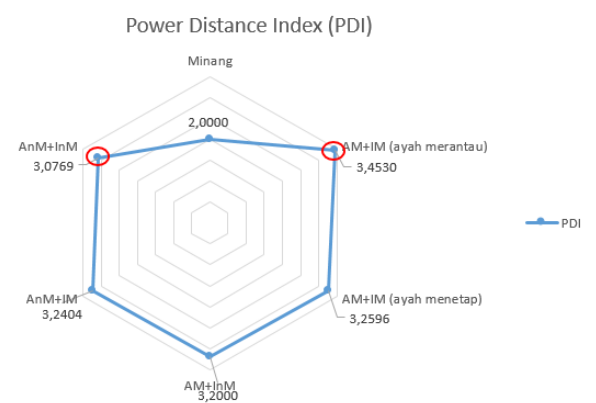

Gambar 1.Kondisi power distance index (PDI) masyarakat Tj. Raya

Gambar di atas menjelaskan bahwa budaya Minangkabau cenderung memiliki nilai power distance index (PDI) yang rendah. Adapun tipe-tipe keluarga yang mengajarkan nilai keteladanan dengan power distance rendah yang condong dekat dengan norma yang diajarkan oleh nenek moyang masyarakat Minangkabau yang juga memiliki nilai power distance rendah adalah keluarga tipe ayah nonMinang dan ibu non-Minang (AnM+InM) serta tipe ayah Minang dan ibu nonMinang (AM+InM). Sedangkan upaya pewarisan yang dilakukan oleh orang tua yang memiliki nilai keteladanan yang bertolak belakang dengan norma yang diajarkan oleh budaya Minangkabau da-lam hal power distance, dilakukan oleh keluarga tipe $\mathrm{AM}+\mathrm{IM}$ ayah merantau dan $\mathrm{AM}+\mathrm{IM}$ ayah menetap.

Nilai power distance index (PDI) adalah menyangkut seberapa dekat atau jauhnya jarak kekuasaan seorang individu/kelompok dengan individu/kelompok lainnya. Dengan kata lain, nilai PDI rendah tidak menerima dan mengakui hierarki yang muncul secara alamiah. Individu ini tidak setuju setiap orang secara kodrati berada pada posisi-posisi tertentu tanpa harus dipersoalkan.

Budaya Minangkabau selalu meng-ajarkan sikap egaliter ${ }^{10}$, dicirikan oleh skor PDI yang cenderung rendah. Anak laki-laki dan perempuan harus sama-sama bisa berkelahi (pintar bermain silat) namun sama-sama juga pintar memasak di dapur. Ayah dan ibu sama-sama berangkat ke danau, ayah memancing sementara ibu mengolah ikannya di pinggir danau. Perubahan yang terjadi saat ini adalah keluarga AM+IM dengan ayah merantau memiliki nilai power distance yang paling besar karena ayah yang biasanya tidak berada di rumah menjadi sering mengandalkan ibu untuk mengajarkan atau melayani keinginan anak. Jika ingin berkeluh kesah, ayah menyuruh anak untuk datang ke ibunya dulu, barulah nanti ibu menyampaikannya kepada ayah. Sikap yang lebih egaliter ditunjukkan oleh keluarga dengan konfigurasi ayah non-Minang dan ibu non-Minang (AnM+InM). Pada keluarga ini, orang tua utamanya mengajarkan kemampuan beradaptasi kepada anak. Mereka menyiapkan anak agar kuat menghadapi situasi sebagai kaum minoritas (oleh karena kedua orang tua non-Minang), suatu keadaan yang mungkin bisa memaksa anak berada pada hierarki terbawah. Anak pun dianjurkan agar rajin menabung mempersiapkan diri untuk hari esok, serta diajarkan agar luwes bersosialisasi supaya mudah diterima oleh masyarakat. Peran mendidik anak dilakukan oleh ayah dan ibu secara bergantian.

\footnotetext{
${ }^{10}$ Egaliter adalah persamaan derajat setiap manusia, duduk sama rendah berdiri sama tinggi 258
} 
Potret Individualism vs Collectivism Masyarakat Tanjung Raya

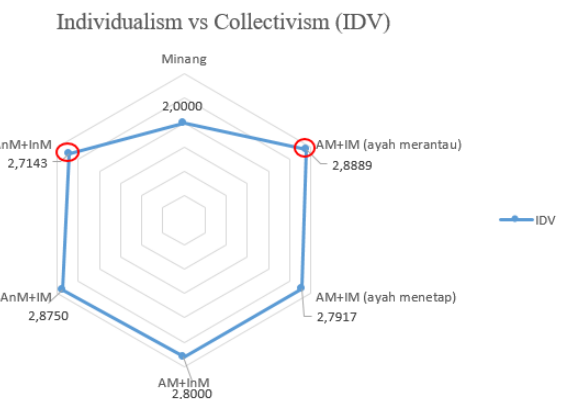

Gambar 2. Kondisi individualism vs collectivism (IDV) masyarakat Tj. Raya

Budaya Minangkabau mengajarkan nilai individualism vs collectivism (IDV) yang rendah. Adapun tipe-tipe keluarga yang mengajarkan norma yang searah dengan ajaran budaya Minangkabau menyangkut nilai IDV yang rendah adalah keluarga tipe ayah non-Minang dan ibu non-Minang (AnM+InM) serta tipe ayah Minang dan ibu Minang dengan ayah menetap (AM+IM ayah menetap). Sedangkan tipe keluarga ayah Minang dan ibu Minang dengan ayah merantau (AM+IM ayah merantau) serta tipe ayah non-Minang dan ibu Minang (AnM+IM) cenderung mengajarkan sikap yang lebih individulistik kepada anak.

Potret masyarakat berdasarkan nilai individualism vs collectivism (IDV) juga tidak berbeda jauh dengan nilai PDI, dimana keluarga dengan konfigurasi ayah non-Minang dan ibu non-Minang (AnM+InM) memiliki nilai yang mendekati nilai IDV yang diajarkan oleh budaya Minang-kabau. Hidup berkelompok selalu dianjur-kan di dalam budaya Minangkabau. Da-lam penerapannya, keluarga tipe ayah non-Minang dan ibu non-Minang (AnM+InM) lebih nyata melaksanakannya, meskipun tujuannya berbeda. Bagi keluarga AnM+InM, hidup berkelompok lebih dimaksudkan untuk menciptakan kenyamanan dan keamanan meskipun kelompok yang dimaksud tidak harus dengan sesama budaya. Bagi ajaran Minangkabau, hidup berkelompok yang dianjurkan lebih ke arah pola uxorilokal ${ }^{11}$. Orang Minang juga cenderung mau membantu orang Minang lainnya di perantauan karena sesama urang awak. Perasaan ini mengasah perilaku hidup berkelompok dengan mengizinkan tamunya menginap di rumah. Kebiasaan ini mengikis sifat individualistis orang Minang. Di dalam falsafah alam juga secara eksplisit terdapat komponen pola awak samo awak yang selain mengajarkan sifat collectivism, juga menanamkan sifat tolong menolong, membalas pemberian ataupun bantuan dari orang lain (short term orientation) serta menikmati hidup sewajarnya (indul-gence). Tidak hanya pola awak samo awak, sebagian besar komponen falsafah alam mengajarkan tentang pentingnya hidup berkelompok, seperti pada konsep harga diri, malu yang tak dapat dibagi, rasa dan periksa, kesamaan dan kebersamaan, seiya sekata, serta hidup bertahan dan mem-pertahankan hidup.

\footnotetext{
${ }^{11}$ Uxorilokal merupakan pola hidup berkelompok bersama dengan keluarga istri
} 
Potret Uncertainty Avoidance Masyarakat Tanjung Raya

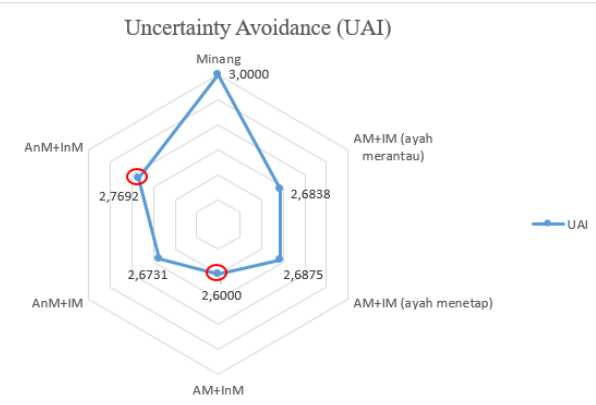

Gambar 3. Kondisi uncertainty avoidance index (UAI) masyarakat Tj. Raya

Budaya Minangkabau cenderung mengajarkan agar masyarakat menjauhkan diri dari ketidakpastian (nilai uncertainty avoidance tinggi). Keluarga yang juga mengajarkan hal yang sama adalah tipe ayah non-Minang dan ibu non-Minang (AnM+InM) serta tipe ayah Minang dan ibu Minang dengan ayah menetap (AM+IM ayah menetap). Sedangkan keluarga yang tidak terganggu dengan ketidakpastian sehingga tidak menjadi komponen penting untuk diwariskan kepada anaknya adalah keluarga tipe ayah Minang dan ibu non-Minang $(\mathrm{AM}+\mathrm{InM})$ serta tipe ayah non-Minang dan ibu Minang (AnM+IM).

Nilai uncertainty avoidance index (UAI) yang diajarkan oleh budaya Minangkabau cenderung tinggi. Nilai terdekat oleh keluarga ayah non-Minang dan ibu non-Minang (AnM+InM) menggambarkan bahwa pada kenyataannya keluarga inilah yang lebih menanamkan sifat waspada akan ketidakpastian kepada anaknya. Sesungguhnya ajaran falsafah alam tentang malu yang tak dapat dibagi, kesamaan dan kebersamaan, seiya sekata, pola penyesuaian yang serasi, serta hidup bertahan dan mempertahankan hidup mengajarkan pentingnya orang Minang untuk mengantisipasi ketidakpastian. Kenyataan di lapangan, justru pada keluarga tipe ayah Minang dan ibu non-Minang (AM+InM) lebih longgar dalam mengajarkan antisipasi pada ketidakpastian kepada anaknya. Kondisi ini bias dengan pemahamannya mereka tentang ajaran hidup bertahan dan mempertahankan hidup. Bagi mereka, komponen ini justru mengajarkan bahwa rezeki sudah ada yang mengatur, nikmati hidup dalam batas wajar karena rezeki bisa dicari kembali, sehingga mereka tidak ketat mengajarkan persistensi dalam hidup. Meskipun mereka sendiri waspada pada situasi yang tidak menentu sehingga menerapkan peraturan yang mengikat pada anak, namun keluarga AM+InM masih belum mengajarkan konsekuensi dari ketidakpastian yang berpotensi dihadapi oleh anaknya kelak.

\section{Potret Masculinity vs Femininity Masyarakat Tanjung Raya}

Masculinity vs Femininity (MAS)

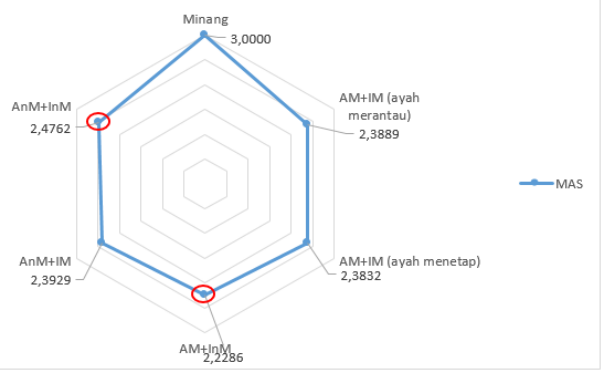

Gambar 4. Kondisi masculinity vs femininity (MAS) masyarakat Tj. Raya 
Ajaran Minangkabau yang lebih maskulin sesuai dengan pola yang diajarkan oleh keluarga tipe ayah non-Minang dan ibu non-Minang (AnM+InM) serta tipe ayah non-Minang dan ibu Minang (AnM+IM). Pada keluarga tipe ayah Minang dan ibu non-Minang (AM+InM) serta tipe ayah Minang dan ibu Minang dengan ayah menetap cenderung mengajarkan femininitas.

Seperti halnya budaya Minangkabau yang cenderung maskulin, keluarga tipe ayah non-Minang dan ibu non-Minang (AnM+InM) juga cenderung lebih mengajarkan nilai-nilai maskulin kepada anaknya. Nilai yang mengedepankan kompetisi, ketegasan, ambisi, dan berorientasi pada materi, pada budaya Minangkabau lebih diartikan agar anak dapat mencapai suatu prestasi yang dibanggakan oleh keluarga. Jadi nilai ambisi yang ditanamkan dalam budaya Minangkabau selalu disandingkan dengan nilai kolektif sehingga prestasi anak dapat menciptakan suatu kebanggaan milik seluruh anggota keluarga, baik keluarga inti, keluarga besar, maupun keluarga luas. Sementara itu di lapangan, keluarga tipe ayah Minang dan ibu non-Minang (AM+InM) lebih senang mengajarkan tentang pentingnya menjaga hu-bungan yang baik agar hidup anak lebih berkualitas. Meskipun keluarga AM+InM mengajarkan nilai-nilai feminin (seperti misalnya: berprestasi itu penting namun tidak untuk berkompetisi karena harus mengutamakan hubungan yang baik terlebih dahulu), namun mereka tetap mempertahankan nilai kelompok (collectivism) yang diajarkan oleh budaya Minangkabau.

\section{Potret Long Term Orientation Masyarakat Tanjung Raya}

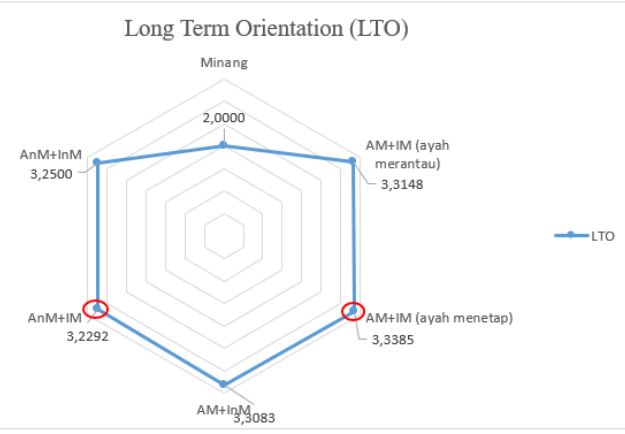

Gambar 5. Kondisi long term orientation (LTO) masyarakat Tj. Raya

Budaya Minangkabau lebih berori-entasi jangka pendek, seperti halnya yang diajarkan juga oleh keluarga tipe ayah non-Minang dan ibu Minang (AnM+IM) serta tipe ayah non-Minang dan ibu non-Minang (AnM+InM). Pada keluarga tipe ayah Minang dan ibu Minang dengan ayah menetap (AM+IM ayah menetap) serta ayah Minang dan ibu Minang dengan ayah merantau (AM+IM ayah merantau) lebih pragmatis.

Budaya Minangkabau mengutamakan short term orientation (long term orientation rendah), yaitu membentuk masyarakat yang lebih menghargai tradisi, menghargai asal usulnya, melestarikan keaslian budayanya, juga bangga terhadap negaranya. Masyarakat yang melaksanakan kewajiban sosialnya seperti bergotong royong dan memiliki tenggang rasa yang tinggi. Sikap tenggang rasa ini juga diajarkan oleh keluarga tipe ayah non-Minang dan ibu Minang (AnM+IM). Semula pengajaran ini bertujuan untuk menanamkan sikap yang sama baiknya terhadap adat ayah maupun adat ibu yang berlainan, akhirnya berkembang menjadi sikap tenggang rasa dalam cakupan yang lebih luas. Lain halnya dengan keluarga tipe ayah Minang dan ibu Minang dengan ayah menetap (AM+IM ayah 
menetap), keluarga ini sangat pragmatis dan berorientasi pada penghargaan terhadap masa depan dan jangka panjang. Bagi mereka, penghargaan merupakan perwujudan terhadap sikap penghematan dan dapat mengarahkan anak menjadi lebih tekun berusaha dan adaptif terhadap keadaan yang senantiasa sering berubah-ubah.

\section{Potret Indulgence vs Restraints Masyarakat Tanjung Raya}

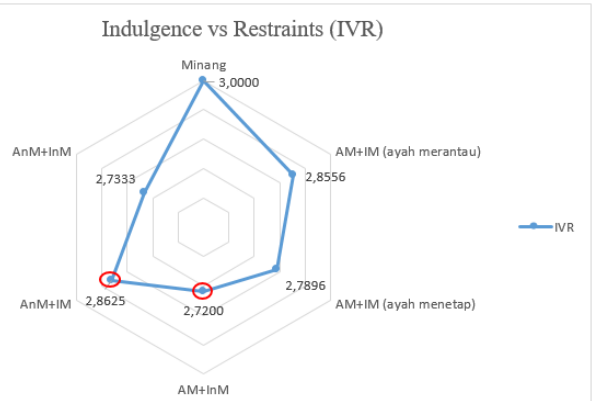

Gambar 6. Kondisi indulgence vs restraints (IVR) masyarakat Tj. Raya

Budaya Minangkabau mengajarkan sikap restraints kepada masyarakatnya. Sama halnya dengan yang diajarkan oleh keluarga tipe ayah non-Minang dan ibu Minang (AnM+IM) serta tipe ayah Minang dan ibu Minang dengan ayah merantau (AM+IM ayah merantau). Pada keluarga tipe ayah Minang dan ibu nonMinang (AM+InM) serta tipe ayah non-Minang dan ibu non-Minang (AnM+InM) lebih membiarkan anak un-tuk menikmati hidup dengan menjadi lebih konsumtif.

Budaya Minangkabau memiliki nilai indulgence vs restraints (IVR) yang tinggi, artinya budaya ini memiliki nilai restraints yang lebih tinggi daripada nilai indulgence. Nilai IVR adalah menyangkut sejauh mana masyarakat berusaha mengendalikan keinginan dan dorongan mereka. Budaya yang lebih restraints lebih menekan tingkat kebutuhan dan mengaturnya dengan menggunakan norma sosial yang ketat, melalui menabung ataupun berinvestasi untuk keperluan jangka panjang. Di dalam ajaran falsafah alam, komponen tentang kesamaan dan kebersamaan, serta seiya sekata meng-ajarkan sikap restraints ini. Kondisi di lapangan, tipe keluarga ayah non-Minang dan ibu Minang (AnM+IM) dan keluarga ayah Minang dan ibu Minang dengan ayah merantau (AM+IM ayah merantau) lebih mengajarkan sikap restraints ini. Uniknya, keluarga tipe ayah Minang dan ibu non-Minang (AM+InM) serta ayah non-Minang dan ibu nonMinang (AnM+InM) yaitu kedua tipe keluarga yang memiliki ibu non-Minang, sangat indulgence. Sikap ini merupakan ciri sebuah masyarakat yang menginginkan kepuasan diri dan kehidupan yang relatif lebih bebas yang berkaitan dengan menikmati hidup dan bersenang-senang. Artinya, keluarga yang memiliki ibu Minang (AM+IM dan AnM+IM) masih memegang prinsip pengaturan hidup dengan menggunakan norma sosial yang ketat. 


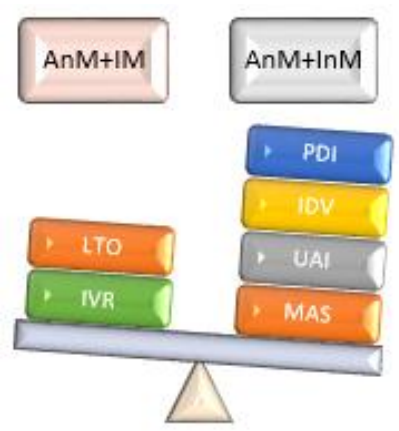

Gambar 7. Keluarga yang dekat dengan ajaran budaya Minangkabau

Gambar di atas menyajikan ilustrasi dua tipe keluarga yang memiliki materi ajaran pewarisan paling sesuai dengan ajaran budaya Minangkabau, dilihat dari dimensi budaya Hofstede. Jika diamati dengan seksama, keduanya sama-sama berasal dari keluarga yang memiliki ayah non-Minang (AnM+InM serta AnM+IM). Kondisi ini disebabkan oleh ayah yang non-Minang cenderung patriarki. Dengan struktur keluarga yang kian berbentuk keluarga inti (ayah, ibu dan anak), ayah yang non-Minang cenderung berlaku sebagai kepala keluarga yang memimpin semua anggota keluarganya. Sebagai pemimpin keluarga, ayah non-Minang lebih mementingkan nilai maskulinitas namun tetap menghargai kebersamaan. Nilai kebersamaan mengikis sifat egonya dan melahirkan sikap toleransi dengan sesama. Oleh karena hidup di zaman yang lebih demokratis, keluarga ini lebih egaliter. Satu lagi hal penting yang dimiliki oleh tipe ini adalah sangat penuh pertimbangan dan selalu menghindari ketidakpastian. Mereka juga menghargai tradisi.

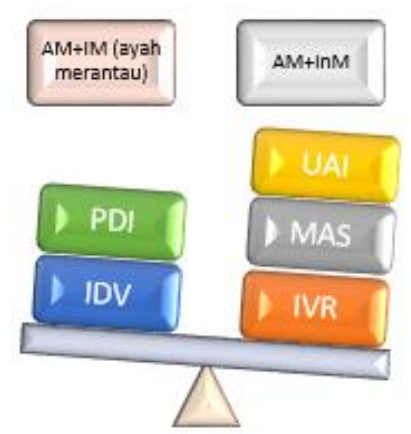

Gambar 8. Keluarga yang jauh dari ajaran budaya Minangkabau

Gambar di atas mengilustrasikan dua tipe keluarga yang mewariskan ajaran yang jauh atau bertolak belakang dengan ajaran budaya Minangkabau. Mereka adalah dari keluarga yang sama-sama memiliki ayah Minang (AM+IM ayah merantau serta $\mathrm{AM}+\mathrm{InM}$ ). Kondisi ini terjadi karena memang budaya Minangkabau mengajarkan femininitas, sehingga ayah Minang berusaha mewariskannya kepada anak-anak. Keluarga ini cenderung santai menikmati hidup dan tidak menghindari ketidakpastian. Pada keluarga AM+IM dengan ayah merantau, sikap hierarkis didapat dari ayah yang tidak dijadikan tempat anak mengadu dan berkeluh kesah. Ayah hanya ingin mendapatkan informasi dari ibu mengenai perkembangan dan keinginan anak. Segala pertimbangan dan kebingungan anak, cukup didiskusikan dengan ibu, lalu ibu berkomunikasi dengan ayah setelah itu. 


\section{KESIMPULAN DAN SARAN}

Potret budaya Minangkabau diambil dari salah satu elemen alam takambang jadi guru yaitu tentang falsafah alam. Di dalam elemen ajaran falsafah alam menurut Hofstede terkandung nilai kompetisi yang tinggi (MAS tinggi), menghindari ketidakpastian yang tinggi (UAI tinggi), dan menganjurkan upaya penekanan tingkat kebutuhan serta pengaturan menggunakan norma sosial yang ketat (IVR tinggi). Masyarakat diajarkan untuk hidup berkelompok (IDV rendah), lebih menghargai tradisi, lebih bangga terhadap budaya dan negara, berkeinginan untuk melestarikan keaslian budaya, lebih menghargai kewajiban sosial, serta lebih senang membalas suatu pemberian dan bantuan dari orang lain (LTO rendah). Budaya Minangkabau juga mengajarkan bahwa hierarki secara kodrati merupakan kemunduran (PDI rendah). Potret masing-masing dimensi Hofstede pada setiap tipe keluarga adalah: Keluarga ayah Minang dan ibu Minang dengan ayah merantau (AM+IM merantau) memiliki dimensi IDV dan PDI yang jauh dari ajaran budaya Minangkabau. Pada keluargaAM+IM menetap hanya memiliki dimensi LTO yang sejalan dengan budaya Minangkabau. Keluarga AM+InM memiliki dimensi IVR, MAS dan UAI yang berjauhan dengan budaya Minangkabau. Keluarga AnM+IM justru memiliki dimensi IVR dan LTO yang dekat dengan ajaran budaya. Ke-luarga AnM+InM memiliki dimensi IDV, MAS, PDI, UAI yang dekat dengan budaya Minangkabau.

\section{DAFTAR PUSTAKA}

Ardial. 2014. Paradigma dan Model Penelitian Komunikasi. Jakarta: Bumi Aksara

Assmann J. 2010. Globalization, Universalism, and the Erosion of Cultural Memory (bab 6) dalam buku Memory in a Global Age: Discourses, Practices and Trajec-tories. New York: Palgrive Mac-Millan Memory Studies,pp. 121-137.

Awe B. 2010. Globalization: Accultu-ration or Cultural Erosion? A Historical Reflection. Journal of Global Initiatives: Policy, Peda-gogy, Perspective. Vol 3 no.2 Globalization and the Unending Frontier.

Bronfenbrenner U.1979. The Ecology of Human Development. Experiments by Nature and Design. Massa-chusetts (US): Harvard University Press.

DeSilvey C. 2017. Curated Decay: Heritage Beyond Saving. Minne-apolis, London: University of Minnesota Press.

Firdaus D.R.S. 2018. Potret Budaya Masyarakat Minangkabau Berdasar-kan Keenam Dimensi Budaya Hofstede. Jurnal Sodality: Jurnal Sosiologi Pedesaan. Vol. 6 no. 2.

Graves E. 2007. Asal Usul Elite Minang-kabau Modern: Respon Terhadap Kolonial Belanda Abad XIX/XX. Jakarta: Yayasan Obor Indonesia.

Hofstede G. 2010. Cultures and Organi-zations: Software of the Mind. London: McGraw-Hill.

Huo Y.P. \& Randall D.M. 1991. Ex-ploring Subcultural Differences in Hofstede's Value Survey: The Case of the Chinese. Asia Pacific Journal of Management, 8. Pp. 159173.

John M.S., Ashgate, Aldershot. 2001. Romancing Decay. Ideas of Deca-dence in European Culture Studies in European Cultural Transition

Jones M.L. 2007. Hofstede - Culturally Questionable? Oxford Business \& Economics Conference. Oxford, UK, 24-26 June 2007. 
Kato, Tsuyoshi. 2005. Adat Minangkabau dan Merantau dalam Perspektif Sejarah. Jakarta: Balai Pustaka.

Koentjaraningrat. 1990. Kebudayaan Mentalitas dan Pembangunan. Jakarta: Gramedia.

McSweeney B. 2002. Hofstede's Model of National Cultural Differences and Their Consequences: A Triumph of Faith a Failure of Analysis. Human Relations Journal Vol. 55(1) pp.89-118. The Tavistock Institute, SAGE Publications.

Mubah A.S. 2011a. Revitalisasi Identitas Kultural Indonesia di Tengah Upaya Homogenisasi Global, dalam Global \& Strategis, Edisi Khusus Desember 2011.

Mubah A.S. 2001b. Strategi Meningkat-kan Daya Tahan Budaya Lokal dalam Menghadapi Arus Globali-sasi, jurnal Unair tahun 2011, volu-me 24, nomor 4, halaman 302-308.

Navis A.A. 1984. Alam Terkembang Jadi Guru. Jakarta: Grafiti Pers.

Prakash D. 2003. The Principles of Co-operation; A Look at the ICA Co-operative Identity Statement. New Delhi:Pamda-Network International.

Scholte, J.A. 2001. The Globalization of World Politics. Oxford: Oxford University Press.

Syafrial. 2015. Pendidikan Keluarga Menurut Islam dalam Budaya Adat Minangkabau. Disertasi Program Pascasarjana Institut Agama Islam Negeri (IAIN), Imam Bonjol Padang.

Tomlinson J. 2003. Globalization and Cultural Identity. Cambridge: Polity Press.

Turner L.H. \& West R. 2006. The Family Communication Sourcebook. Cali-fornia (US): Sage Publication.

Wahab E.O., Odunsi S.O., Ajiboye O.E. 2012. Causes and Consequences of Rapid Erosion of Cultural Values in a Traditional African Society. Journal of Anthropology, vol 2012, Article ID 327061, 7 pages. Hin-dawi Pubishing Corporation. 